\title{
Associations between local descriptive norms for overweight/obesity and insufficient fruit intake, individual-level diet, and 10-year change in body mass index and glycosylated haemoglobin in an Australian cohort
}

Suzanne J. Carroll ${ }^{1 *}$, Theo Niyonsenga ${ }^{1,2}$, Neil T. Coffee ${ }^{1,2}$, Anne W. Taylor $^{3}$ and Mark Daniel ${ }^{1,2,4}$

\begin{abstract}
Background: Descriptive norms (what other people do) relate to individual-level dietary behaviour and health outcome including overweight and obesity. Descriptive norms vary across residential areas but the impact of spatial variation in norms on individual-level diet and health is poorly understood. This study assessed spatial associations between local descriptive norms for overweight/obesity and insufficient fruit intake (spatially-specific local prevalence), and individual-level dietary intakes (fruit, vegetable and sugary drinks) and 10-year change in body mass index (BMI) and glycosylated haemoglobin $\left(\mathrm{HbA}_{1}\right)$.

Methods: $\mathrm{HbA}_{1 c}$ and $\mathrm{BMI}$ were clinically measured three times over 10 years for a population-based adult cohort $(n=4056)$ in Adelaide, South Australia. Local descriptive norms for both overweight/obesity and insufficient fruit intake specific to each cohort participant were calculated as the prevalence of these factors, constructed from geocoded population surveillance data aggregated for $1600 \mathrm{~m}$ road-network buffers centred on cohort participants' residential addresses. Latent growth models estimated the effect of local descriptive norms on dietary behaviours and change in $\mathrm{HbA}_{1 c}$ and $\mathrm{BMI}$, accounting for spatial clustering and covariates (individual-level age, sex, smoking status, employment and education, and area-level median household income).

Results: Local descriptive overweight/obesity norms were associated with individual-level fruit intake (inversely) and sugary drink consumption (positively), and worsening $\mathrm{HbA}_{1 c}$ and BMI. Spatially-specific local norms for insufficient fruit intake were associated with individual-level fruit intake (inversely) and sugary drink consumption (positively) and worsening $\mathrm{HbA}_{1 c}$ but not change in BMI. Individual-level fruit and vegetable intakes were not associated with change in $\mathrm{HbA}_{1 c}$ or BMl. Sugary drink consumption was also not associated with change in $\mathrm{HbA}_{1 c}$ but rather with increasing BMI.

(Continued on next page)
\end{abstract}

\footnotetext{
* Correspondence: suzanne.carroll@canberra.edu.au

${ }^{1}$ Centre for Research and Action in Public Health, Health Research Institute,

University of Canberra, Bruce, ACT, Australia

Full list of author information is available at the end of the article
}

(C) The Author(s). 2018 Open Access This article is distributed under the terms of the Creative Commons Attribution 4.0 International License (http://creativecommons.org/licenses/by/4.0/), which permits unrestricted use, distribution, and reproduction in any medium, provided you give appropriate credit to the original author(s) and the source, provide a link to the Creative Commons license, and indicate if changes were made. The Creative Commons Public Domain Dedication waiver (http://creativecommons.org/publicdomain/zero/1.0/) applies to the data made available in this article, unless otherwise stated. 


\begin{abstract}
(Continued from previous page)
Conclusion: Adverse local descriptive norms for overweight/obesity and insufficient fruit intake are associated with unhealthful dietary intakes and worsening $\mathrm{HbA}_{1 \mathrm{c}}$ and $\mathrm{BMl}$. As such, spatial variation in lifestyle-related norms is an important consideration relevant to the design of population health interventions. Adverse local norms influence health behaviours and outcomes and stand to inhibit the effectiveness of traditional intervention efforts not spatially tailored to local population characteristics. Spatially targeted social de-normalisation strategies for regions with high levels of unhealthful norms may hold promise in concert with individual, environmental and policy intervention approaches.
\end{abstract}

Keywords: Descriptive norms, Cardiometabolic risk, Overweight and obesity, Dietary behaviour

\section{Background}

Cardiovascular disease (CVD) and type 2 diabetes (cardiometabolic disorders) are preventable, yet combined these conditions represent approximately 40\% of the health burden in Organisation for Economic Co-operation and Development (OECD) countries [1]. Similarly, the prevalence of overweight and obesity, risk factors for CVD and type 2 diabetes, continue to rise globally $[2,3]$. Individual-level dietary choices are implicated in the development of overweight/obesity and cardiometabolic risk and disease, as well as other chronic diseases [4-8]. Diet-related diseases are among the leading health challenges of our time [4]. It is therefore essential to understand the drivers of individual dietary choices and how these relate to health outcomes.

Diets rich in fruits and vegetables, and low in sugar sweetened beverages are associated with better health outcomes [6, 9-12]. Such food consumption behaviours are influenced by a multitude of inter-related individual and environmental factors. At the individual-level these include age, sex, socioeconomic status (SES), attitudes to food and health, motivation and habit $[13,14]$. In general, women, older adults, and individuals with higher incomes eat more fruits and vegetables [15-17].

Environmental influences on food consumption behaviours include physical and social environment factors. The physical environment includes accessibility and availability of various foods (e.g., healthful versus unhealthful food options) [13]. Literature reviews have documented reasonably consistent associations between accessibility to supermarkets and healthier diets and lower body weight, while greater accessibility to convenience stores and fast-food outlets is associated with poorer diets and higher body weight $[18,19]$.

A key influence on individual health behaviour and outcomes is the social environment which includes social pressures expressed as social norms [13]. A social norm is an expectation about behaviour that is shared by a group of people [20]. Social norms are collective constructs providing shared rules of conduct that can influence individual-level choices [21]. Such social norms can be conceptualised as two distinct, yet related, influences, injunctive and descriptive norms [22]. Injunctive norms represent what ought to be done, what is socially sanctioned while, descriptive norms are what most people actually do, what is normal [22]. A descriptive norm can therefore be considered the prevalence of a behaviour or trait [23, 24]. Though commonly conceived of as functioning within social networks, social norms also vary spatially (i.e., between and within areas). Previous research further defines social norms according to the source of influence, where "subjective" norms represent the influence of important others such as friends and family (e.g., social networks), and "local" norms represent the influence derived from people who are co-located regardless of any emotional connection [25-27]. Thus, a local descriptive norm can be considered as a local prevalence of a behaviour or trait [23, 28], an approach we have taken here.

Reviews of experimental studies concluded that social modelling and behavioural conformity shape food consumption amounts and choices (e.g., high energy versus low energy) [29-31]. Similarly, diet and dietary intentions have been linked in cross-sectional and longitudinal studies to the eating behaviours of social group members including family and friends [32, 33]. Social contagion studies have reported clustering and contagion (i.e., spread of a trait or behaviour over time) of alcohol consumption, smoking behaviour and obesity within social networks (i.e., subjective descriptive norms) [34-38].

Much of the research regarding the influence of social norms, injunctive or descriptive, has focused on social networks. The influence of spatially defined, local descriptive norms on health behaviour and outcomes has rarely been evaluated. One Dutch longitudinal study (13 years of follow up) reported a greater odds of an adult becoming overweight if they lived in a neighbourhood with a greater prevalence of overweight residents [39]. Our recent work found that local descriptive norms for overweight/obesity and insufficient fruit intake predicted worsening trajectories of $\mathrm{HbA}_{1 \mathrm{c}}$ [28]. However, a potential association between local descriptive norms and dietary intake of fruits, vegetables, or sugary drinks, or change in body mass index (BMI), was not assessed.

It is likely that local descriptive norms impact cardiometabolic outcomes including $\mathrm{BMI}$ and $\mathrm{HbA}_{1 \mathrm{c}}$ by influencing 
individual-level health behaviours such as dietary intake. Explicit testing of this mediating mechanism is needed to support biological plausibility of the link between local descriptive norms and health outcomes. Biological plausibility supports causal inference [40,41]. Understanding the mechanisms linking local descriptive norms to health outcomes is necessary to inform the development of targeted intervention strategies. This study aimed to evaluate the direct effects of local descriptive norms for overweight/obesity and insufficient fruit intake on individual-level dietary intakes of fruits, vegetables and sugary drinks and 10-year change in $\mathrm{HbA}_{1 \mathrm{c}}$ and BMI. In addition, this study assessed whether individuallevel dietary intake was a mediating mechanism linking local descriptive norms to change in health outcomes.

\section{Methods}

This longitudinal observational study was part of the Place and Metabolic Syndrome (PAMS) Project which evaluated the role of residential environmental features in shaping individual-level cardiometabolic risk and received multiple ethics approvals (see Declarations). PAMS used data from the North West Adelaide Health Study (NWAHS), a population-based biomedical cohort of randomly selected adults (over 18 years of age) investigating the prevalence of chronic conditions and their associated risk factors [42]. Four thousand and fifty six of 8213 eligible adults participated in the NWAHS at baseline $(49.4 \%$ of eligible sample). The NWAHS includes clinical data collected at three waves over 10 years: Wave $1(2000-03, n=4056)$, Wave 2 (2005-06, $n=3205,79 \%$ of baseline sample) and Wave 3 (2008-10, $n=2487$, 61.3\% of baseline sample).

A geographic information system (GIS) was used to spatially join NWAHS data with data from the wholly separate South Australian Monitoring and Surveillance System (SAMSS) survey. The SAMSS is a population surveillance survey that monitors population trends in chronic diseases and their risk factors, geocoded at the street address [43, 44]. SAMSS data were used to construct local descriptive norms measures (environmental exposures).

\section{Study area}

The NWAHS was conducted in the northern and western regions of metropolitan Adelaide (Fig. 1), the capital city of South Australia. In 2001 (baseline), these regions accounted for $38 \%$ of Adelaide's 1.1 million population $[45,46]$.

Environmental associations with health behaviours and outcomes differ between urban and rural regions [47]. The study area was therefore limited to urban areas only, defined as Census Collection Districts (CDs) with a population density of $>200$ persons per hectare and contiguous with other $>200$ persons per hectare CDs [45].

\section{Cohort participants}

Sociodemographic, behavioural and residential address (used to create a geo-reference point enabling spatial joining with other data) information were collected at each NWAHS wave using Computer-Assisted Telephone Interviews (CATIs) and self-reported paper questionnaires. Biomedical data, including fasting blood samples and anthropometric information, were collected during clinic visits at each wave.

Households within the NWAHS region (defined by postcode) were randomly selected from the Australian Electronic White Pages telephone directory and the adult (18 years or over) who most recently had their birthday asked to participate in the study. The baseline sample was not statistically different from the Adelaide metropolitan population [48] by sex, education or household income. However, older individuals ( $\geq 45$ years) were over-represented and younger individuals (18-29 years) were under-represented. A multi-strategy approach was used to minimise cohort attrition, including the use of study promotional material, newsletters and birthday cards, and tracking based on the White Pages telephone directory and the State Electoral Roll [49]. Written informed consent was obtained prior to each data collection wave. Further information on data collection and cohort profile is available elsewhere [42, 49].

\section{Measures \\ Outcome measures}

Outcome measures were $\mathrm{HbA}_{1 \mathrm{c}}$ concentration (\%) and $\mathrm{BMI}$ calculated from height and weight measured during clinic visits at each wave. Height (without shoes) was measured using a wall-mounted stadiometer. Weight (without shoes, light clothing) was taken using standard digital scales. BMI was calculated as kilograms per metre squared $\left(\mathrm{kg} / \mathrm{m}^{2}\right) . \mathrm{HbA}_{1 \mathrm{c}}$ concentration, reflecting 2-3 month timeaveraged blood glucose level [50], was assayed from fasting blood samples collected at each wave [42].

\section{Local descriptive norms}

Local descriptive norms for overweight/obesity and insufficient fruit intake were defined within road-network buffers constructed by radiating $1600 \mathrm{~m}$ (1 mile) along the road-network in all possible directions from each participant's residential address. The $1600 \mathrm{~m}$ distance represents the distance covered by an average adult walking at a comfortable pace $(5 \mathrm{~km} /$ hour) for approximately $20 \mathrm{~min}$ [51] and has previously been used in studies assessing the impact of the local food environment on health outcomes (e.g., [52-54]).

Concordance between the $1600 \mathrm{~m}$ road-network buffers and geocoded SAMSS participant addresses (for adults 18 years and over) was established using a GIS. Individuallevel SAMSS data were extracted according to this 


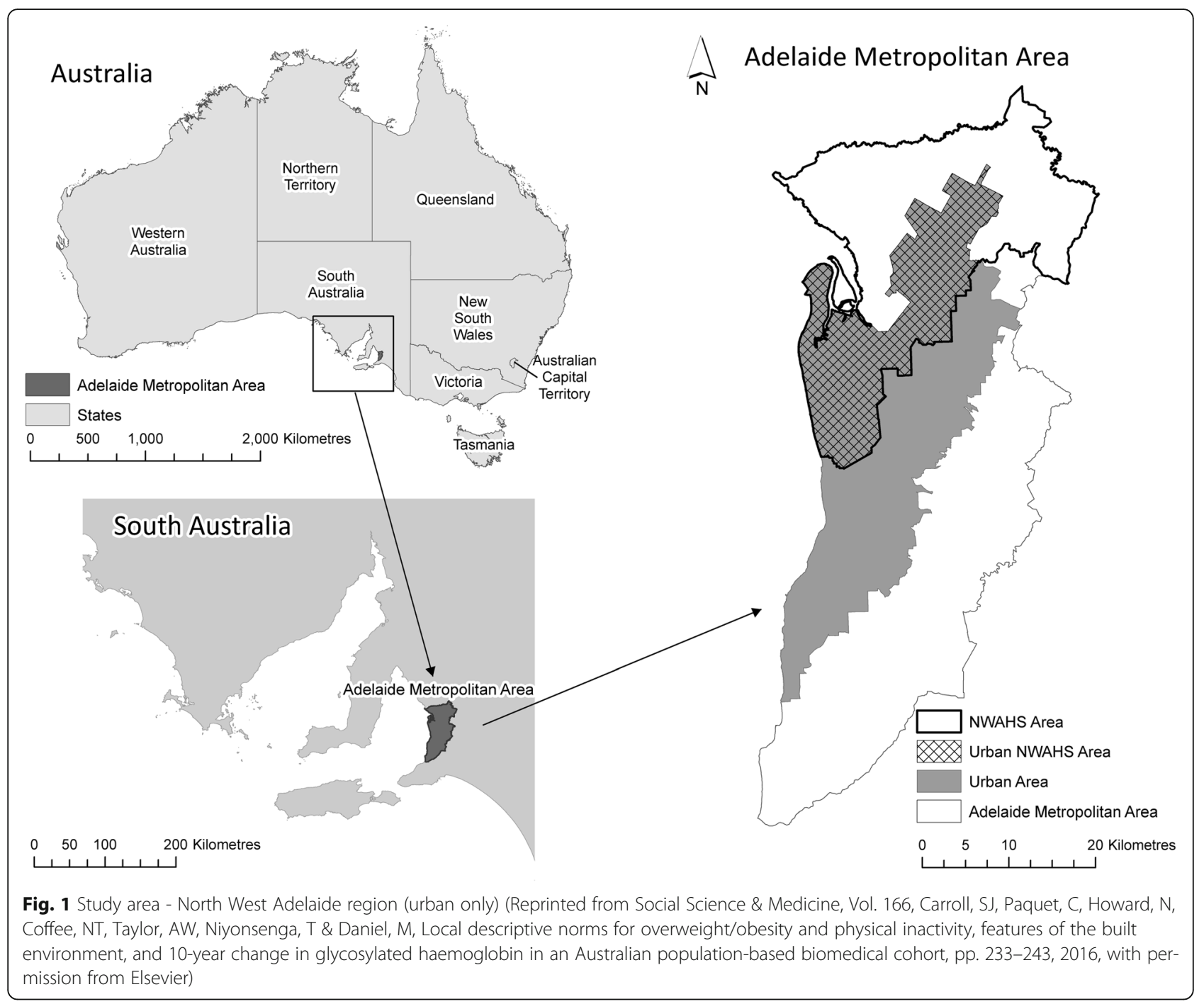

concordance, then spatially aggregated to construct bufferspecific prevalence rates for overweight/obesity $(\mathrm{BMI} \geq$ $\left.25 \mathrm{~kg} / \mathrm{m}^{2}\right)$ and insufficient fruit intake $(<2$ servings per day), per standard health recommendations [55, 56]. As appropriate weightings for standardisation were not available for the buffers used, prevalence rates were unstandardised in keeping with the precedent of Blok and colleagues [39]. The use of other weightings such as for the Adelaide metropolitan region could artificially reduce or inflate spatial variation. Processing of individuallevel data was performed by the data custodians to protect the confidentiality of SAMSS participants. More information on the SAMSS is available elsewhere $[43,44]$.

Geocoded SAMSS data were not available for years prior to 2006. Hence, local descriptive norms are not contemporaneous with the NWAHS baseline but instead represent normative exposures from Wave 2 to 3 . To maximise SAMSS participant numbers for NWAHS participant buffers, data were pooled across 2006-2010.
Aggregated norms data for buffers with less than 50 SAMSS participants or less than five participants per measurement category were not released by data custodians. This protects the confidentiality of SAMSS participants and provides more reliable local descriptive norms estimates. Detail on the construction of local descriptive norms measures is available elsewhere [21, 28]. Local descriptive norms measures were standardised (i.e., z-scores with a mean of zero) prior to analyses.

\section{Individual-level dietary intakes}

Individual-level dietary measures were self-reported fruit, vegetable and sugary drink intakes. Such dietary intake information was collected in 2007 using an additional CATI subsequent to the main Wave 2 CATI. The method of collection for dietary information was questions from the Australian National Health Survey [57]. Information included self-reported usual daily servings of fruits and vegetables, and weekly frequency of sugary drink consumption. 
Fruit and vegetable questions asked participants to report the usual number of serves of fruits and vegetables they consumed per day (with examples of what constitutes a serve). Questions about the frequency of soft drink, cordial or sports drinks had a range of reporting options from "never", "rarely", or number of times per year through to number of times per day. For our purposes, sugary drink consumption responses were recoded for expression as frequency per week with "rarely" and "never" coded as zero consumption per week.

Due to their inclusion in statistical models as both predictors and outcomes, fruit and vegetable intake measures (usual serves per day) were log transformed to improve their distributional characteristics. Log transformation of sugary drink consumption (weekly frequency) was considered but rejected due to the zero-inflated distribution. Thus, a two-category version of the measure was constructed, defined as no sugary drink intake versus sugary drink intake. Other categorisations were considered (e.g., three categories) but given the complexity of the SEM models with sugary drinks analysed as a mediating variable (i.e., involving use as both an outcome and a predictor), ordinal expression was not possible. Use of the three-category version (as two dummy coded variables) within models resulted in large increases in the AIC and the BIC indicating that the two-category version had better model fit.

\section{Covariates}

Individual and area-level covariates included in statistical models were individual-level age, sex, employment status (full-time, part-time, or not in the work force), level of education (university graduate or not), marital status (married/de facto, or single) and smoking status (current smoker or non-smoker), and area-level income (median household income).

Individual-level covariates were selected based on previous research regarding dietary behaviour and cardiometabolic risk, and analyses to identify factors predicting loss to follow-up (logistic regression was used to determine variables associated with attrition, defined as nonattendance for clinical assessment) [21]. Incomplete clinic attendance (missing $\mathrm{HbA}_{1 \mathrm{c}}$ and $\mathrm{BMI}$ information at follow ups) was predicted by male sex, young age, low household income, not being in the work-force, being a smoker, and not being married (or de facto). These measures were therefore included in statistical models to satisfy the analytic criterion of missing at random [58].

Area-level SES was operationalised as median weekly household income, commonly used in research assessing associations between area-level SES and health [59]. To avoid multicollinearity, only one area-level SES measure was included in the models. Data were extracted from the 2006 Australian Population and Housing Census
[60] at the smallest available unit, the Census District (CD, average of 220 dwellings [61]), and aggregated using the weighted average of values from CDs intersected by the NWAHS participant buffers. Further information on this method is available elsewhere [21, 28].

\section{Analyses}

Figure 2 illustrates the direct and indirect effects being tested. These effects were estimated using latent growth models in Mplus (version 7.4, Muthen \& Muthen) with a structural equation modelling (SEM) approach and a Monte Carlo integration estimation-based process [62, 63]. Full information maximum likelihood (FIML) was used to estimate parameter estimates with standard errors (computed using a sandwich approach) robust to nonnormality and non-independence of observations. Use of FIML allowed the inclusion of cases with missing dietary information $[64,65]$. The SEM approach enables the simultaneous estimation of direct and indirect effects within one model as opposed to the use of multiple regression models [62, 66, 67].

Trajectories of outcomes, $\mathrm{HbA}_{1 \mathrm{c}}$ and $\mathrm{BMI}$, were modelled as latent growth factors with random effects for participant variation in baseline values (intercept), and participant-specific rate of changes in outcomes (slope) over time. Each model estimated the influence of a single local descriptive norm on one dietary intake (e.g., fruit intake) and the rate of change in one outcome variable (latent growth factor slope for $\mathrm{HbA}_{1 \mathrm{c}}$ or $\left.\mathrm{BMI}\right)$, and the influence of dietary intake on rate of change in the outcome variable. Models accounted for spatial clustering within suburbs and are reported both unadjusted and adjusted for individuallevel covariates and area-level income predicting outcome latent growth factor intercept and slope. Indirect effects were calculated as the product of coefficients for path a and path $b$ using the model constraint estimation approach [62]. Statistical significance was set at alpha $=0.05$.

Separate sets of analyses assessed relationships with the two outcome measures, $\mathrm{HbA}_{1 \mathrm{c}}$ and BMI. Each analysis sample was restricted to individuals who did not have CVD or diabetes type 2 at baseline $\left(\mathrm{HbA}_{1 \mathrm{c}}\right.$ sample), or who were not obese (obese being defined as BMI > 30) at baseline (BMI outcome sample). These restrictions were applied to reduce the influence of a potential ceiling affect as, on average, the NWAHS cohort had worsening health trajectories. This aligns with health expectations based on associations between aging and normative, age-related increases in $\mathrm{HbA}_{1 \mathrm{c}}$ and BMI.

\section{Results}

Sample loss due to inclusion criteria is presented in Table 1. From the 2797 NWAHS participants meeting the initial inclusion criteria, four sub-samples (highlighted in bold in Table 1) were constructed based on outcome 


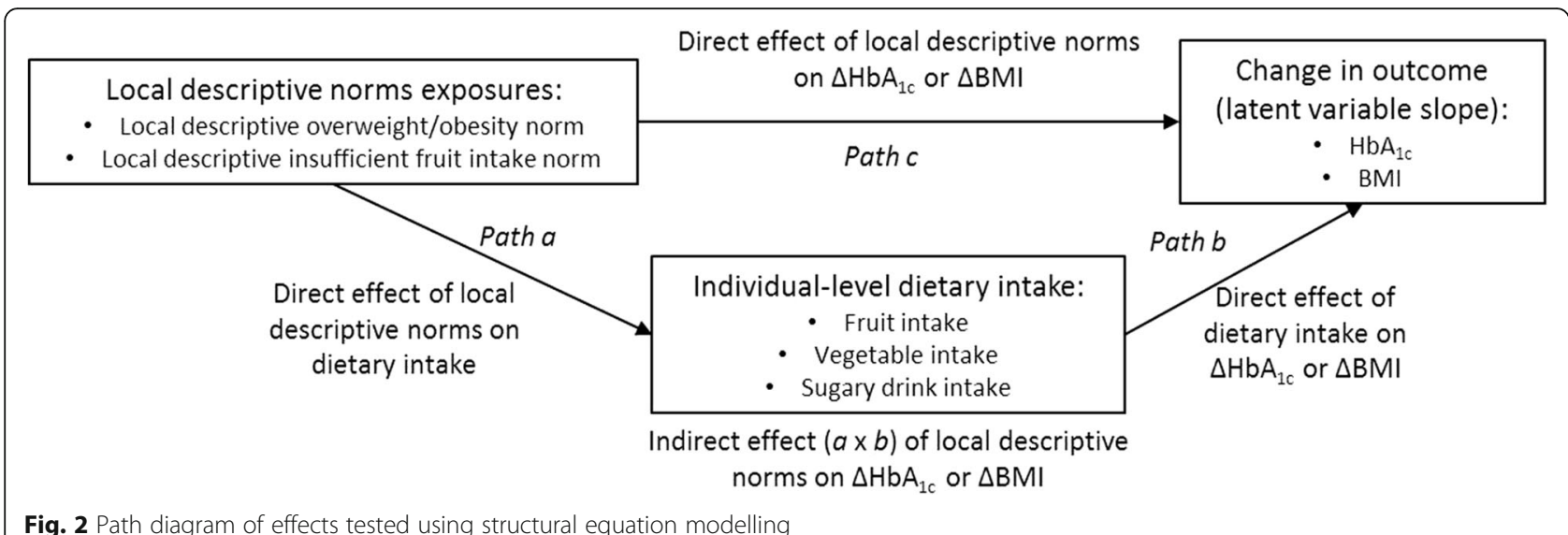

Fig. 2 Path diagram of effects tested using structural equation modelling

measure and availability of local-area descriptive norms information.

Characteristics of the four analytic samples and the features of their environments are provided in Table 2 . There were no notable differences between the two $\mathrm{HbA}_{1 \mathrm{c}}$ analytic samples, or between the two BMI analytic samples.

Intraclass correlations (ICCs) were calculated from covariance parameter estimates obtained from a multilevel (three-level) empty model (i.e., with no predictors) performed in SAS (version 9.4, SAS Institute Inc., Cary, North Carolina) [68]. These ICCs describe the degree of similarity of $\mathrm{HbA}_{1 \mathrm{c}}$ concentrations or BMI for repeat measures within participants and for clustering of participants within suburbs. Estimates indicated moderate correlation at the individual-level (repeated $\mathrm{HbA}_{1 \mathrm{c}}$ measures over time: $\mathrm{ICC}=0.57$; repeated $\mathrm{BMI}$ measures over time: ICC 0.80 ) and relatively low to very low correlation at the suburb level $\left(\mathrm{HbA}_{1 \mathrm{c}} \mathrm{ICC}=0.01\right.$; $\left.\mathrm{BMI} \mathrm{ICC}=0.002\right)$, consistent with previous reports [69].

Results of the fitted analytic models are presented in Tables 3 and 4. Estimation of the latent growth factors for $\mathrm{HbA}_{1 \mathrm{c}}$ (with no predictors) indicated average baseline $\mathrm{HbA}_{1 \mathrm{c}}$ of $5.42 \%$ (95\% confidence interval [CI] 5.39 to $5.44, p<0.0001$ ), and an annual increase (worsening) of 0.04 percentage points $(95 \%$ CI 0.029 to $0.040, p<0.0001$ ) (results not shown). Similarly, average baseline BMI was $25.26 \mathrm{~kg} / \mathrm{m}^{2}$ (95\% CI 25.12 to $\left.25.39 \mathrm{~kg} / \mathrm{m}^{2}, p<0.0001\right)$ with an annual increase of $0.12 \mathrm{~kg} / \mathrm{m}^{2}$ (95\% CI 0.10 to $0.14, p<0.0001$ ).

Results from adjusted models are reported unless noted otherwise. Greater local descriptive norms for overweight/ obesity were statistically significantly associated with fruit intake (inverse, $\beta=-0.025,95 \%$ CI -0.047 to -0.002 , $p=0.030)$, sugary drink intake $(\beta=0.028,95 \%$ CI 0.004 to 0.053, $p=0.023$ ), and increasing $\mathrm{HbA}_{1 \mathrm{c}}$ over time (i.e., worsening, $\beta=0.009,95 \%$ CI 0.004 to $0.013, p<0.0001$ ). Greater local descriptive norms for overweight/obesity were not associated with individual-level vegetable intake. Similarly, greater local descriptive norms for insufficient fruit intake were statistically significantly associated with individual-level fruit intake (inverse, $\beta=-0.030$, $95 \%$ CI -0.052 to $-0.007, p=0.010$ ), sugary drink intake

Table 1 Inclusion criteria and derivation of the three analytic samples

\begin{tabular}{|c|c|c|c|}
\hline Criteria & \multicolumn{2}{|l|}{$\mathrm{n}$} & Reason for reduced numbers \\
\hline NWAHS sample (W1) & \multicolumn{2}{|l|}{4056} & - \\
\hline Geocoded (W1) & \multicolumn{2}{|l|}{4041} & 15 participants with invalid residential addresses \\
\hline Residing in urban area (W1) & \multicolumn{2}{|l|}{3887} & 154 participant addresses outside the urban area \\
\hline Participated in Wave 2 & \multicolumn{2}{|l|}{3362} & 525 participants did not participate in Wave 2 \\
\hline \multirow[t]{2}{*}{ Did not move (W1 to W2) } & \multicolumn{2}{|l|}{2797} & 565 participants moved between Waves 1 and 2 \\
\hline & $H b A_{1 c}$ & $B M l$ & Of participants meeting previous criteria $(n=2797)$ : \\
\hline CVD/diabetes free at Wave 1 & 2325 & - & 472 participants had CVD or Type 2 diabetes at Wave 1 \\
\hline Not obese at Wave $1(\mathrm{BMI}<30)$ & - & 1982 & 815 participants were obese at Wave 1 \\
\hline Covariate data (W1) & 2261 & 1926 & $64\left(\mathrm{HbA}_{1 c}\right.$ sample) and 56 (BMl sample) participants lacked covariate data at Wave 1 \\
\hline LDN: Overweight/obesity & 1908 & 1630 & 353 ( $\mathrm{HbA}_{1 c}$ sample) and 296 (BMl sample) participants lacked overweight/obesity norm data \\
\hline LDN: Insufficient fruit intake & 1966 & 1673 & 295 ( $\mathrm{HbA}_{1 c}$ sample) and 253 (BMI sample) participants lacked local insufficient fruit intake norm data \\
\hline
\end{tabular}

Abbreviations: $B M I$ body mass index, $C V D$ cardiovascular disease, $H b A_{1 c}$ glycosylated haemoglobin, $L D N$ local descriptive norms, $N W A H S$ North West Adelaide Health Study, W1, Wave 1; W2, Wave 2 
Table 2 Sample characteristics and features of areas for each of the four analytic samples

\begin{tabular}{|c|c|c|c|c|}
\hline \multirow[b]{2}{*}{ Measure } & \multicolumn{2}{|l|}{$\Delta \mathrm{HbA}_{1 \mathrm{c}}$ analytic samples } & \multicolumn{2}{|l|}{$\Delta \mathrm{BMI}$ analytic samples } \\
\hline & $\begin{array}{l}\text { LDN: Overweight/obesity } \\
n=1908\end{array}$ & $\begin{array}{l}\text { LDN: Insufficient fruit intake } \\
n=1966\end{array}$ & $\begin{array}{l}\text { LDN: Overweight/obesity } \\
n=1630\end{array}$ & $\begin{array}{l}\text { LDN: Insufficient } \\
\text { fruit intake } \\
n=1673\end{array}$ \\
\hline Individual-level characteristics & Mean (SD) & Mean (SD) & Mean (SD) & Mean (SD) \\
\hline Length of follow-up (years) & $7.85(1.05)$ & $7.85(1.05)$ & $7.90(1.03)$ & $7.89(1.03)$ \\
\hline Age (years) & $49.9(15.2)$ & $49.9(15.2)$ & $51.6(16.3)$ & $51.6(16.2)$ \\
\hline Sex (female) n (\%) & $1052(55.1 \%)$ & $1085(55.2 \%)$ & $830(50.9 \%)$ & $853(51.0 \%)$ \\
\hline Current smoker n (\%) & $335(17.6 \%)$ & $345(17.6 \%)$ & $288(17.7 \%)$ & $294(17.6 \%)$ \\
\hline Education (university graduate) n (\%) & $250(13.1 \%)$ & $254(12.9 \%)$ & $211(12.9 \%)$ & $213(12.7 \%)$ \\
\hline Marital status (married) n (\%) & $1227(64.3 \%)$ & $1260(64.1 \%)$ & $1031(63.3 \%)$ & $1060(63.4 \%)$ \\
\hline Not employed n (\%) & $816(42.8 \%)$ & $844(42.9 \%)$ & $748(45.9 \%)$ & $768(45.9 \%)$ \\
\hline Fruit intake (daily count of servings) & $(n=1587) 1.5(1.0)$ & $(n=1638) 1.5(1.0)$ & $(n=1337) 1.5(1.0)$ & $(n=1375) 1.5(1.0)$ \\
\hline Vegetable intake (daily count of servings) & $(n=1583) 2.5(1.4)$ & $(n=1633) 2.5(1.4)$ & $(n=1332) 2.5(1.4)$ & $(n=1370) 2.5(1.4)$ \\
\hline Drinks sugary drinks n (\%) & $(n=1588) 923(58.1 \%)$ & $(n=1639) 952(58.1 \%)$ & $(n=1337) 730(54.6 \%)$ & $(n=1375) 751(54.6 \%)$ \\
\hline $\mathrm{HbA}_{1 \mathrm{c}}$ & $(n=1904) 5.43(0.45)$ & $(n=1962) 5.43(0.45)$ & $(n=1610) 5.52(0.66)$ & $(n=1653) 5.52(0.67)$ \\
\hline $\mathrm{BMI}\left(\mathrm{kg} / \mathrm{m}^{2}\right)$ & $27.57(5.20)$ & $27.59(5.20)$ & $25.27(2.86)$ & $25.28(2.86)$ \\
\hline Environmental features & Mean (SD) & Mean (SD) & Mean (SD) & Mean (SD) \\
\hline 1600 m buffer area $\left(\mathrm{km}^{2}\right)$ & $4.71(2.40)$ & $4.72(2.41)$ & $4.78(2.41)$ & $4.78(2.42)$ \\
\hline LDN: Overweight/obesity & $62.85(6.18)$ & - & $62.65(6.15)$ & - \\
\hline $\mathrm{n}_{\text {(SAMSS participants) }}$ per buffer & $95.6(31.5)$ & - & $97.2(31.7)$ & - \\
\hline LDN: Insufficient fruit intake & - & $53.79(6.57)$ & - & $53.36(6.63)$ \\
\hline$n$ (SAMSS participants) per buffer & - & $100.3(33.6)$ & - & $102.0(33.6)$ \\
\hline $\begin{array}{l}\text { Area-level median household income } \\
\text { (A\$/week) }\end{array}$ & 838.45 (131.64) & $837.13(134.52)$ & $839.06(130.29)$ & $838.15(132.57)$ \\
\hline
\end{tabular}

Abbreviations: $B M I$ body mass index, $H b A_{1 c}$ glycosylated haemoglobin, $L D N$ local descriptive norms, $S D$ standard deviation

$(\beta=0.025$, 95\% CI 0.002 to $0.048, p=0.032)$, and increasing $\mathrm{HbA}_{1 \mathrm{c}}(\beta=0.007 \mathrm{CI} 0.002$ to $0.011, p=0.005)$, but were not associated with vegetable intake. Fruit, vegetable and sugary drink intakes were not associated with change in $\mathrm{HbA}_{1 \mathrm{c}}$ and there were no statistically significant indirect effects between the local descriptive norms and change in $\mathrm{HbA}_{1 \mathrm{c}}$ through dietary behaviour.

In models assessing change in BMI, local descriptive norms for overweight/obesity were statistically significantly associated with individual-level sugary drink intake $(\beta=0.030,95 \% \mathrm{CI} 0.003$ to $0.058, p=0.028)$ and increasing BMI over time $(\beta=0.020$, CI 0.004 to 0.036, $p=0.012$ ), but not fruit or vegetable intake. Local descriptive norms for insufficient fruit intake were inversely associated with individual-level fruit intake $(\beta-0.027,95 \% \mathrm{CI}$ -0.048 to $-0.006, p=0.012)$ but not statistically significantly associated with vegetable intake, sugary drink intake, or change in BMI. In unadjusted models, fruit, vegetable and sugary drink intakes were each associated with change in BMI, though only the estimate for sugary drink intake remained statistically significant after adjusting for covariates (sugary drink predicting change in BMI in local descriptive overweight/obesity norms models: $\beta=0.044,95 \%$ CI 0.011 to $0.077, p=0.009$; and in local descriptive insufficient fruit intake norms models: $\beta=0.041,95 \%$ CI 0.008 to $0.075, p=0.016$ ).

In unadjusted models, there was a statistically significant indirect effect between greater local descriptive norms for insufficient fruit intake and increasing BMI through individual-level fruit intake. However, this indirect effect was not statistically significant after accounting for covariates. There were no statistically significant indirect effects for either of the local descriptive norms and change in BMI in covariate-adjusted models.

\section{Discussion}

This study found that local descriptive overweight/obesity norms were associated with individual-level fruit intake (inversely), sugary drink intake (positively), and worsening $\mathrm{HbA}_{1 \mathrm{c}}$ and BMI over 10 years. Similarly, local descriptive insufficient fruit intake norms were associated with individual-level fruit intake (inversely), sugary drink intake (positively), and worsening $\mathrm{HbA}_{1 \mathrm{c}}$ but not change in BMI. Unexpectedly, individual-level fruit, vegetable and sugary drink intakes were not associated with change in $\mathrm{HbA}_{1 \mathrm{c}}$. Fruit and vegetable intakes were associated with 


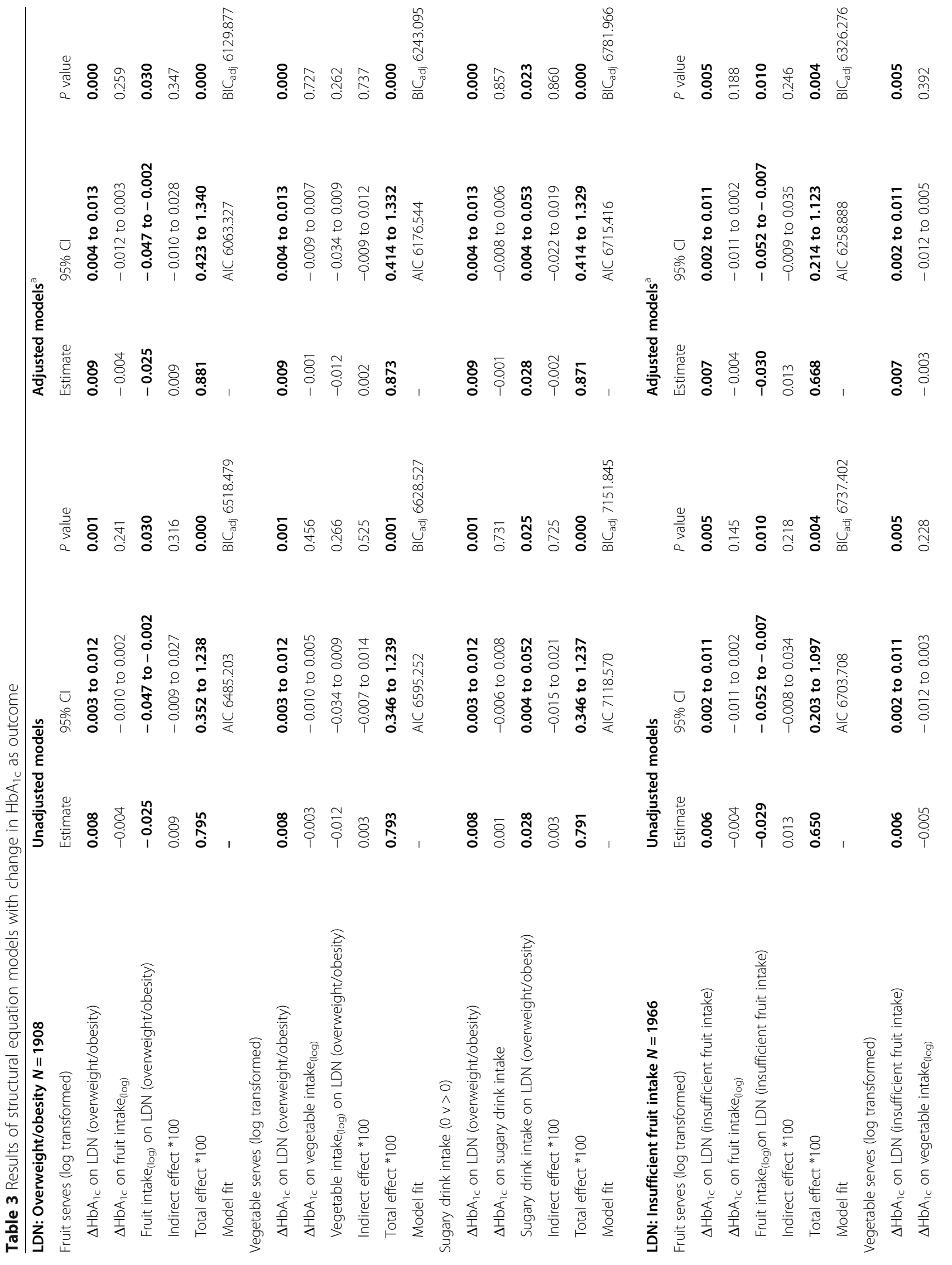




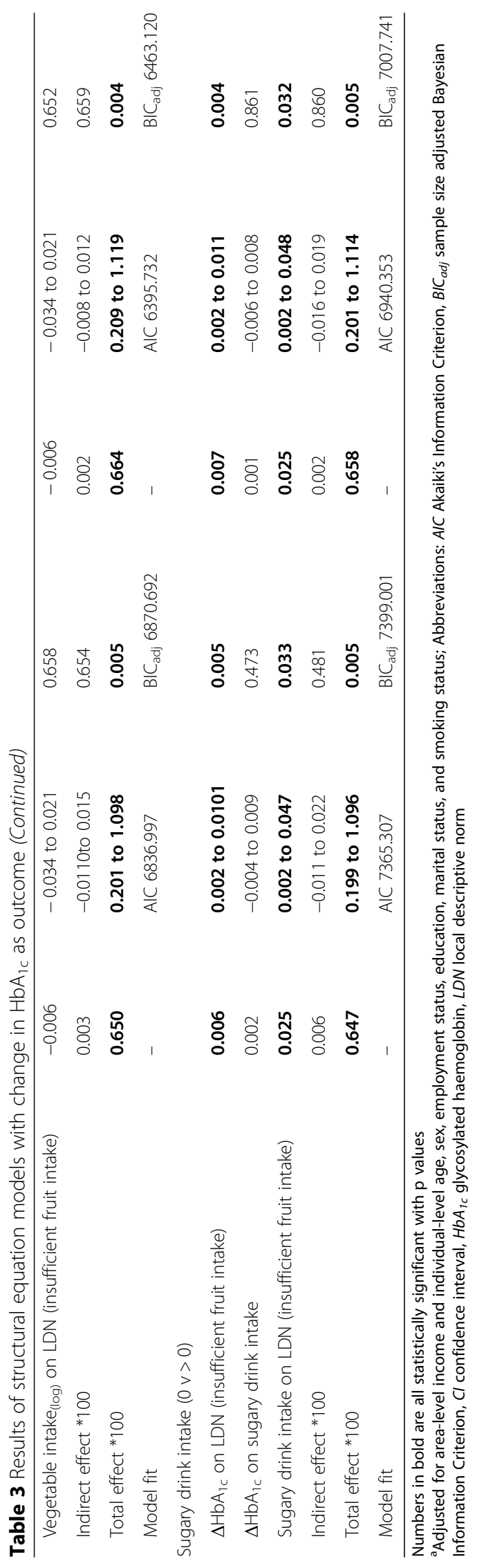




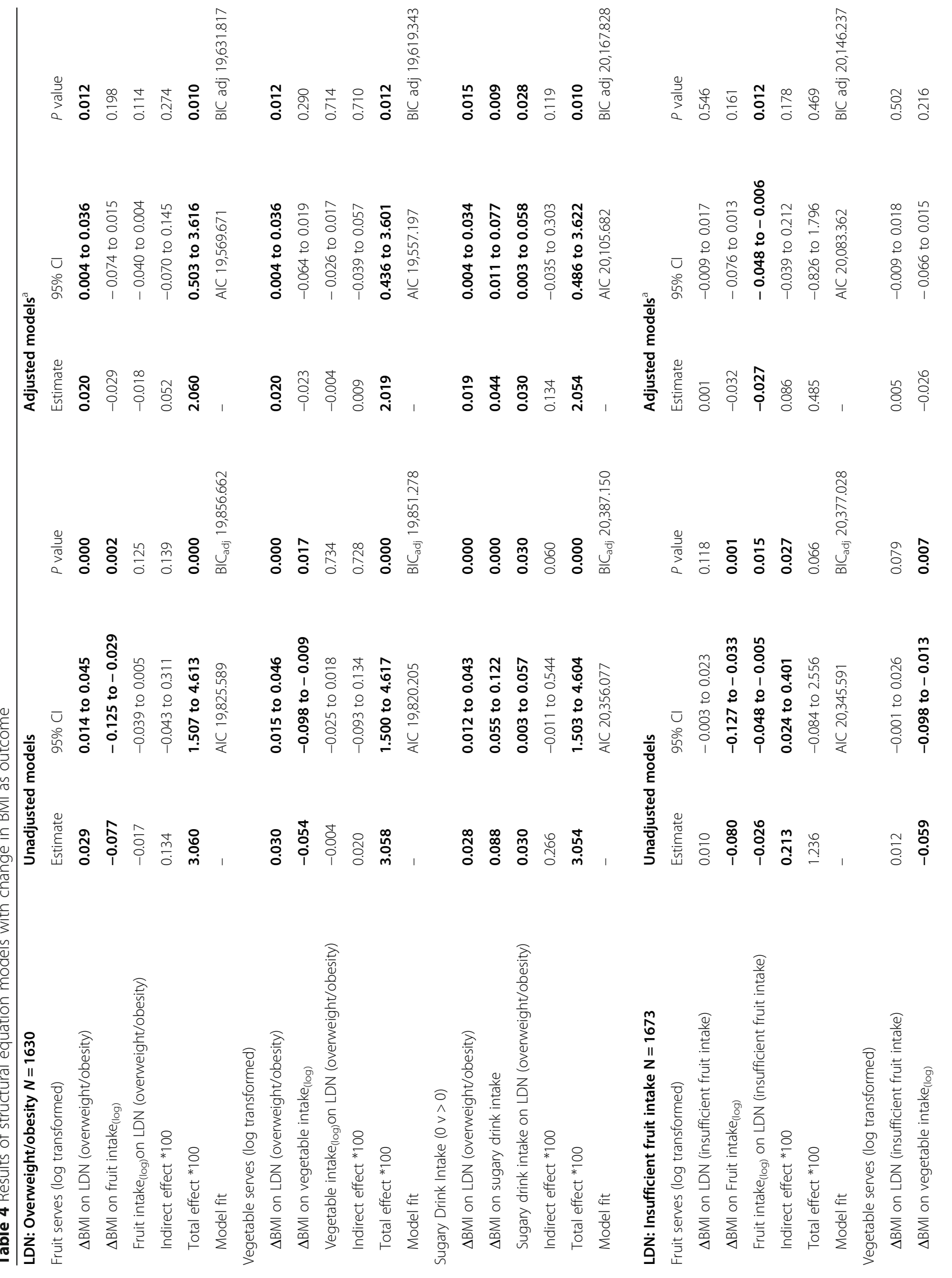




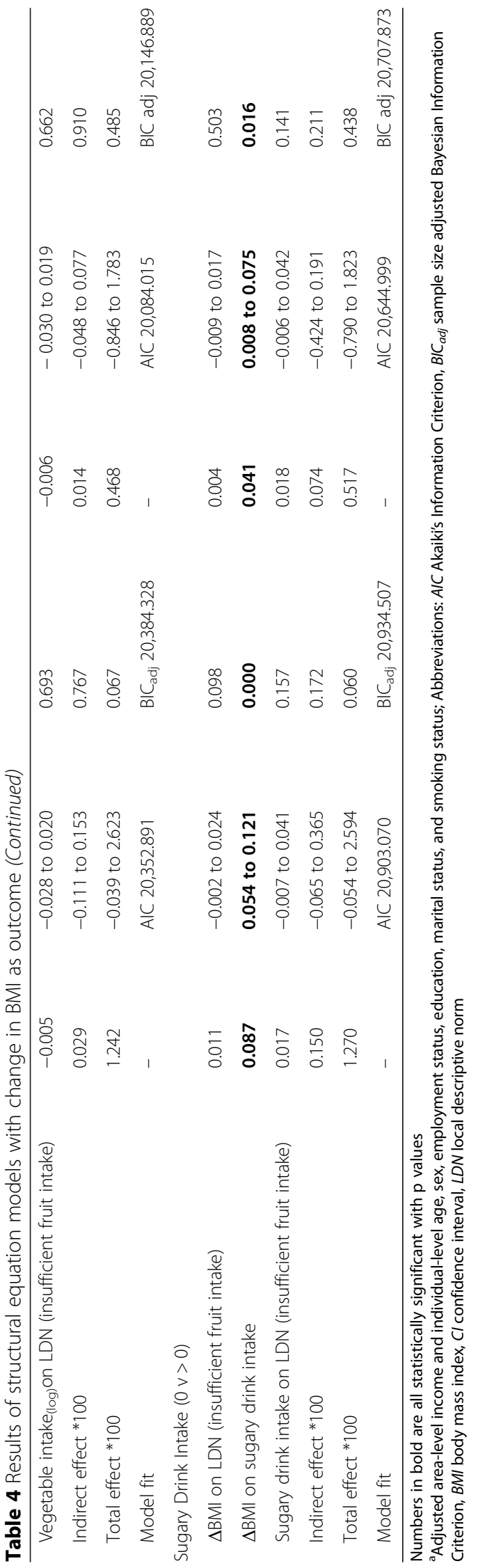


change in BMI (protective effect), but in unadjusted models only. Sugary drink intake alone was associated with change in BMI (worsening) in models accounting for individual-level covariates and area-level SES. There was a statistically significant indirect effect between greater local descriptive insufficient fruit intake norms and increase in BMI through lesser individual-level fruit intake, but again, this was only evident in models unadjusted for covariates.

Previous work by us found that greater local descriptive norms for overweight/obesity and insufficient fruit intake were each associated with worsening $\mathrm{HbA}_{1 \mathrm{c}}$ over 10 years [28]. These associations remained after accounting for the availability of fast food and healthful food resources and area-level SES. The current study builds on and expands this previous work by assessing associations with dietary intakes and change in BMI, and explicitly testing the potential mediating pathway of individual-level dietary intake.

As expected, greater local descriptive overweight/obesity norms were associated with increasing BMI, consistent with the few previous studies conducted. A Dutch study reported that normal weight adults residing in neighbourhoods with a greater prevalence of overweight were more likely to become overweight during 13 years of follow-up [39]. Similarly, analyses conducted within social networks have reported cross-sectional clustering and longitudinal spread (contagion) of obesity [35, 70]. The implications are that both subjective (i.e., within social networks) and local descriptive overweight/obesity norms affect individual-level health, and that further research is needed to elucidate any potential interactions between these sets of influences.

Little evidence exists to explain how descriptive norms influence individual body size and cardiometabolic risk. The clustering and spread of obesity within social networks is hypothesised to reflect socially shared norms about the acceptability of a larger body size, and socially shared behaviours [35]. If normative pressure to conform to healthy body weight is reduced where the descriptive norm denotes a larger, less healthy body size, this then could result in reduced motivation to follow diet and exercise health recommendations. Our findings support this notion. In addition, our results linking local insufficient fruit intake norms and individual-level fruit intake support the premise of socially shared behaviours at a local area level, thus both proposed mechanisms have support.

Previous studies of the influence of descriptive dietary norms on individual-level diet have observed associations like ours. A cross-sectional Australian study of disadvantaged women found that self-reported (and self-interpreted) perceived descriptive norms (defined neither in relation to one's place of residence, nor in relation to a social group) were associated with self-reported dietary intakes [71]. Greater perceived norms for fast-food consumption and sugary drink intake were positively associated with greater fast food and sugary drink intakes, respectively. Similarly, greater perceived norms for healthy eating were positively associated with individual fruit and vegetable intake [71]. However, a cross-sectional design precluded inference on directionality, and self-reported information from the same individuals was used for the perceived norm and individual behaviour. Thus the findings could reflect a "false consensus effect" where beliefs about the behaviours of others are based on one's own behaviours [72].

An experimental study within a university food court setting at lunch time, reported healthy descriptive norms messaging ("Every day more than 150 [name of university] students have a tossed salad for lunch here") resulted in a greater number of individuals choosing to consume healthy food (defined as tossed salad) compared to a control condition [73]. For our study, that the local descriptive norms were associated with fruit and sugary drink intake but not vegetable intake may reflect greater difficulties in obtaining and regularly eating vegetables and a greater dislike of vegetables compared with fruits and sugary drinks. Research on differences in perceptions around fruits, vegetables and sugary drinks and influences that may moderate normative effects on dietary intakes is needed.

This study did not find associations between individuallevel fruit, vegetable, and sugary drink intakes and change in $\mathrm{HbA}_{1 \mathrm{c}}$. Further, even though we observed associations between dietary intakes and change in BMI, only the association between sugary drink intake and increasing BMI remained after accounting for sociodemographic covariates and area-level SES. These findings were unexpected, as a greater consumption of fruits and vegetables, and a restricted intake of sugary drink are widely-accepted predictors of healthy body weight and protective against cardiometabolic disease [4, 10]. Not all studies concur, however. A cross-sectional study of Malaysian adults with type 2 diabetes reported a greater intake of vegetables was associated with greater $\mathrm{HbA}_{1 \mathrm{c}}$ level, though this contrary finding could be due to the cooking methods used as vegetables are often stir-fried or cooked with water or coconut milk in Malaysia [74]. Previous studies (e.g., $[15-17,75])$ have reported greater fruit and vegetable intakes amongst individuals who were female, older, and with higher incomes, factors which were included as covariates in analytic models for the current study. Consequently, the loss of association for fruit and vegetable intake with change in BMI upon model adjustment may be due to over-adjustment. The lack of association between dietary intakes and $\mathrm{HbA}_{1 \mathrm{c}}$, however, is not explained by covariance with other measures as this lack of association was apparent in unadjusted and adjusted models. This may reflect imprecision in the measurement of self-reported diet behaviour which could bias results to the null.

The only indirect effect found was in unadjusted models and only between local descriptive insufficient fruit intake 
norms and change in BMI through individual fruit intake. There were no statistically significant indirect effects of local descriptive norms on change in $\mathrm{HbA}_{1 \mathrm{c}}$ or $\mathrm{BMI}$ through dietary behaviours in adjusted models. This reflects the lack of associations between fruit and vegetable intakes and change in $\mathrm{BMI}$ and $\mathrm{HbA}_{1 \mathrm{c}}$. The lack of a statistically significant indirect effect for sugary drink intake as the mediator between local descriptive overweight/ obesity norms and change in BMI may be due to the size of the coefficients for the associations on the pathway. In unadjusted models this indirect effect was close to statistical significance. Though none of the indirect effects were significant in this sample, this may not reflect a broader lack of association, particularly as the findings were potentially driven by the unexpected lack of association between dietary intake and health outcomes. Future research testing individual-level dietary intake as a link between local descriptive health-related norms and health outcomes, with different samples, would help unravel whether this issue is specific to our sample.

Assessment of other potential mechanisms linking local descriptive norms to health outcomes is also needed. For associations between local descriptive overweight/obesity norms and $\mathrm{HbA}_{1 \mathrm{c}}$ or $\mathrm{BMI}$, this could include physical activity behaviour as physical activity is implicated in each health outcome and may be motivated by local normative pressures to conform. However, our analysis assessing the indirect effect of local descriptive overweight/obesity norms on change in $\mathrm{HbA}_{1 \mathrm{c}}$ through physical activity behaviour found only a small partial mediation effect [76]. Other potential pathways include other behavioural factors (e.g., other diet factors, sedentary behaviour) as well as psychosocial and stress-related pathways [77]. Moreover, the effect of such pathways may be modified by other individual or environmental factors $[28,78]$.

Significant associations between local descriptive norms, dietary intakes and health outcomes reported in this study highlight the importance of descriptive norms to health outcomes. Interventions aiming to improve dietary behaviour and health outcomes must consider the local normative environment. Areas with adverse local normative conditions may be resistant to behaviour change interventions. Though injunctive norms messages can promote the importance of healthful behaviour, injunctive norms can be undermined by opposing descriptive norms $[22,79,80]$. Importantly, descriptive norms may be used to promote healthful behaviours. This could include descriptive norms messaging strategies aligned with injunctive norms as well as environmental strategies aiming to influence perceptions of normative behaviour.

Individuals do not wish to deviate substantially from descriptive norms, therefore, the framing of descriptive norms messages needs to be carefully considered [81]. Messages need to be positively framed with a majority ruling (e.g., most people enjoy eating fruit regularly) [78, 82]. Environmental strategies can be used to manipulate perceptions of norms, thus hopefully positively influencing behaviour. One study manipulated the size of shopping cart partitions identified as being for fresh fruits and vegetables, reporting larger partitions increased purchasing of these items [83]. Other studies have reported a portion size effect where a larger portion size is associated with greater food intake (e.g., [84]). Policies could be used to influence such factors, along with food pricing, availability of healthful and unhealthful foods, and product placement (e.g., within supermarkets), all of which may influence food purchasing and intake, and the social acceptability of food options.

\section{Strengths and limitations}

Strengths of this study include the use of an explicit definition of the type of norm being assessed, and the construction of local descriptive norms from a wholly separate survey, thus avoiding same sample bias and the false consensus effect $[72,85]$. While both samples (NWAHS and SAMSS) used in this research were drawn from the same population and are each considered broadly reflective of that population, there remains the possibility of some level of sampling bias which could vary between samples. However, in representing environmental exposures that cannot be constructed from locational databases, the use of a separate survey sample is recommended and has commonly been used in research regarding place influences on health (e.g., [86-88].

Our longitudinal design supports causal inference through temporality of observations, and reduces the likelihood of reverse causation [40]. Most studies reporting associations between where we live and health behaviours or other outcomes are cross-sectional. Moreover, as much of the research reporting the influence of food behaviour related norms has been in experimental settings, and based on individuals, assessing the relationships within a freeliving population adds external validity to such findings. The NWAHS cohort is broadly representative of the Adelaide population and the findings of this study should be generalisable to similar populations residing within similar urban residential environments.

The outcome measures used in this study, $\mathrm{HbA}_{1 \mathrm{c}}$ and $\mathrm{BMI}$, were clinically assessed and each expressed in a continuous format. The use of clinically assessed measures avoids self-report bias, particularly relevant to BMI. Expressing the outcome measure in a continuous format provides greater information on severity of risk, more precisely reflecting the magnitude of change over time. Such measures provide greater statistical power than categorised measures [89]. Individual-level dietary and sociodemographic information was self-reported and is thus subject to potential self-report bias. Similarly, local descriptive 
norms were constructed from aggregated self-reported information. If BMI is under-reported and fruit intake over-reported [90, 91], then the absolute values of the local descriptive norms (i.e., buffer specific prevalence rates) may be under-estimated. However, the relative comparison of local descriptive norms should not be greatly affected.

Finally, though this study sought to minimise confounding and reduce bias due to cohort attrition by including covariates within fitted models, there remains the possibility of residual confounding due to unmeasured influences. Of note, changes in local descriptive norms may have cooccurred with changes in individual-level behaviour in response to some unmeasured factor. Environmental influences on individual-level health outcomes may act through multiple interdependent pathways whilst being subject to an assortment of potential confounders. Complex systems approaches, such as agent-based modelling, may be useful in efforts seeking to understand the complex causal processed likely to be at work [92-95].

\section{Conclusion}

Local descriptive norms for overweight/obesity and insufficient fruit intake were associated with less healthful dietary intakes of fruits, vegetables and sugary drinks, and worsening trajectories of cardiometabolic risk $\left(\mathrm{HbA}_{1 \mathrm{c}}\right.$ and BMI). Local descriptive health-related norms are arguably under-recognised influences on individual-level behaviour and outcomes. Local descriptive norms therefore require consideration in intervention strategies aiming to reduce population risk of chronic diseases.

\section{Abbreviations \\ AIC: Akaiki's Information Criterion; $\mathrm{BIC}_{\mathrm{adj}}$ : sample size adjusted Bayesian Information Criterion; BMI: Body mass index; CATI: Computer-Assisted Telephone Interview; CDs: Census Collection Districts; Cl: Confidence interval; CVD: Cardiovascular disease; FIML: Full information maximum likelihood; GIS: Geographic information system; $\mathrm{HbA}_{1 c}$ : Glycosylated haemoglobin; ICC: Intraclass correlation; LDN: Local descriptive norms; NWAHS: North West Adelaide Health Study; OECD: Organisation for Economic Co-operation and Development; PAMS: Place and Metabolic Syndrome; SAMSS: South Australian Monitoring and Surveillance System; SD: Standard deviation; SEM: Structural equation modelling; SES: Socioeconomic status; W1: Wave 1; W2: Wave 2}

\section{Acknowledgments \\ The authors acknowledge the contributions of Eleonora Dal Grande and Simon Fullerton in preparation of the SAMSS data. SAMSS is owned by SA Health, Adelaide, South Australia. All collected source data are maintained and managed by Population Research and Outcomes Studies, The University of Adelaide. The opinions expressed in this work are those of the authors and may not represent the position or policy of SA Health. We are grateful for the interest and commitment of NWAHS cohort participants. We appreciate the contributions of research support staff involved in NWAHS recruitment and clinical follow up.}

\section{Funding}

The PAMS project was funded by National Health and Medical Research Council (NHMRC) projects (\#570150 and \#631917). The funding sources had no involvement with study design, data collection, analysis and interpretation of results, writing this manuscript or choice of journal.

\section{Availability of data and materials}

These data cannot be made publicly available. The ethics approval granted for this research do not include consent for the sharing of the datasets that support the analyses and conclusions contained within this article. The data are spatial in nature with risk of participant identifiability and breach of confidentiality. In addition, the provider of longitudinal cohort data, a branch of the state government, has declined against these data being made publicly available.

\section{Authors' contributions}

SJC and MD conceived and designed the study. NTC, MD and SJC developed and constructed key environmental measures. SJC analysed the data with input from TN. SJC and MD contributed to interpretation of results. SJC wrote the manuscript, and MD, NTC, TN and AWT revised it critically for important intellectual content. All authors approved the final manuscript.

\section{Ethics approval and consent to participate}

This study was part of the Place and Metabolic Syndrome (PAMS) Project which assessed environmental factors in relation to cardiometabolic risk. The PAMS Project received ethics approval from the University of South Australia (P029-10 and P030-10), Central Northern Adelaide Health Service (Queen Elizabeth Hospital; Application No. 2010010), and the South Australian Department for Health and Ageing (Protocol No. 354/03/2013 and HREC/13/ $\mathrm{SAH} / 53$ ) Human Research Ethics Committees. Written informed consent of NWAHS cohort participants was obtained prior to each wave of data collection.

\section{Consent for publication}

This section is not applicable as the research presented in this manuscript is not a case study, nor does not contain any individual person's data in any form.

\section{Competing interests}

The authors declare they have no competing interests.

\section{Publisher's Note}

Springer Nature remains neutral with regard to jurisdictional claims in published maps and institutional affiliations.

\section{Author details}

${ }^{1}$ Centre for Research and Action in Public Health, Health Research Institute, University of Canberra, Bruce, ACT, Australia. ${ }^{2}$ Spatial Epidemiology \& Evaluation Research Group, School of Health Sciences and Centre for Population Health Research, University of South Australia, Adelaide, Australia. ${ }^{3}$ Discipline of Medicine, The University of Adelaide, Adelaide, SA, Australia. ${ }^{4}$ Department of Medicine, The University of Melbourne, St Vincent's Hospital, Melbourne, VIC, Australia.

Received: 9 November 2017 Accepted: 6 May 2018

Published online: 18 May 2018

\section{References}

1. Organisation for Economic Co-operation and Development. Cardiovascular disease and diabetes: policies for better health and quality of care. Paris: OECD Publishing; 2015.

2. World Health Organization. Global status report on noncommunicable diseases 2014. Geneva: World Health Organization; 2014.

3. Organisation for Economic Co-operation and Development. Health at a glance 2015. Paris: OECD Publishing; 2015.

4. Mozaffarian D. Dietary and policy priorities for cardiovascular disease, diabetes, and obesity. Circulation. 2016;133(2):187.

5. Aune D, Keum N, Giovannucci E, Fadnes LT, Boffetta P, Greenwood DC, Tonstad S, Vatten LJ, Riboli E, Norat T. Whole grain consumption and risk of cardiovascular disease, cancer, and all cause and cause specific mortality: systematic review and dose-response meta-analysis of prospective studies. BMJ Brit Med J. 2016;353:i2716.

6. Wang X, Ouyang Y, Liu J, Zhu M, Zhao G, Bao W, Hu FB. Fruit and vegetable consumption and mortality from all causes, cardiovascular disease, and cancer: systematic review and dose-response meta-analysis of prospective cohort studies. BMJ Brit Med J. 2014;349:g4490.

7. Luo C, Zhang Y, Ding Y, Shan Z, Chen S, Yu M, Hu FB, Liu L. Nut consumption and risk of type 2 diabetes, cardiovascular disease, and all-cause mortality: a systematic review and meta-analysis. Am J Clin Nutr. 2014;100(1):256-69. 
8. Afshin A, Micha R, Khatibzadeh S, Mozaffarian D. Consumption of nuts and legumes and risk of incident ischemic heart disease, stroke, and diabetes: a systematic review and meta-analysis. Am J Clin Nutr. 2014;100(1):278-88.

9. Threapleton DE, Greenwood DC, Evans CEL, Cleghorn CL, Nykjaer C, Woodhead C, Cade JE, Gale CP, Burley VJ. Dietary fibre intake and risk of cardiovascular disease: systematic review and meta-analysis. BMJ Brit Med J. 2013;347:f6879.

10. Malik VS, Popkin BM, Bray GA, Després J-P, Hu FB. Sugar-sweetened beverages, obesity, type 2 diabetes mellitus, and cardiovascular disease risk. Circulation. 2010;121(11):1356-64.

11. Malik VS, Popkin BM, Bray GA, Després J-P, Willett WC, Hu FB. Sugarsweetened beverages and risk of metabolic syndrome and type 2 diabetes: a meta-analysis. Diabetes Care. 2010;33(11):2477-83.

12. Nguyen B, Bauman A, Gale J, Banks E, Kritharides L, Ding D. Fruit and vegetable consumption and all-cause mortality: evidence from a large Australian cohort study. Int J Behav Nutr Phy. 2016;13(1):9.

13. Brug J. Determinants of healthy eating: motivation, abilities and environmental opportunities. Fam Pract. 2008;25(Suppl 1):i50-5.

14. van't Riet J, Sijtsema SJ, Dagevos H, De Bruijn G-J. The importance of habits in eating behaviour. An overview and recommendations for future research. Appetite. 2011;57(3):585-96.

15. Drewnowski A, Rehm CD. Socioeconomic gradient in consumption of whole fruit and 100\% fruit juice among US children and adults. Nutri J. 2015;14(1):3.

16. Hoy MK, Goldman JD, Moshfegh AJ. Differences in fruit and vegetable intake of U.S. adults by sociodemographic characteristics evaluated by two methods. J Food Compos Anal. 2017;64(1):97-103.

17. Australian Bureau of Statistics. 4364.0.55.001 - National Health Survey: First Results, 2014-15 2015. http://www.abs.gov.au/ausstats/abs@.nsf/mf/4364.0. 55.001. Accessed 12 Oct 2017.

18. Leal C, Chaix B. The influence of geographic life environments on cardiometabolic risk factors: a systematic review, a methodological assessment and a research agenda. Obes Rev. 2011;12(3):217-30.

19. Larson NI, Story MT, Nelson MC. Neighborhood environments: disparities in access to healthy foods in the U.S. Am J Prev Med. 2009;36(1):74-81.

20. Liefbroer AC, Billari FC. Bringing norms back in: a theoretical and empirical discussion of their importance for understanding demographic behaviour. Population, Space and Place. 2010;16(4):287-305.

21. Carroll SJ. The contributions of compositional and contextual features of local residential areas to the evolution of cardiometabolic risk over ten years in a population-based biomedical cohort, Doctoral Thesis. Adelaide: School of Health Sciences, University of South Australia; 2017.

22. Cialdini RB, Reno RR, Kallgren CA. A focus theory of normative conduct: recycling the concept of norms to reduce littering in public places. J Pers Soc Psychol. 1990;58(6):1015-26.

23. Carroll SJ, Paquet C, Howard NJ, Coffee NT, Taylor AW, Niyonsenga T, Daniel M. Local descriptive norms for overweight/obesity and physical inactivity, features of the built environment, and 10-year change in glycosylated haemoglobin in an Australian population-based biomedical cohort. Soc Sci Med. 2016;166:233-43.

24. Higgs S. Social norms and their influence on eating behaviours. Appetite. 2015;86:38-44

25. Kormos C, Gifford R, Brown E. The influence of descriptive social norm information on sustainable transportation behavior: a field experiment. Environ Behav. 2015;47(5):479-501.

26. Carrus G, Bonnes M, Fornara F, Passafaro P, Tronu G. Planned behavior and "local" norms: an analysis of the space-based aspects of normative ecological behavior. Cogn Process. 2009;10(2):198-200.

27. Fornara F, Carrus G, Passafaro P, Bonnes M. Distinguishing the sources of normative influence on proenvironmental behaviors: the role of local norms in household waste recycling. Group Processes \& Intergroup Relations. 2011;14(5):623-35

28. Carroll SJ, Paquet C, Howard NJ, Coffee NT, Adams RJ, Taylor AW, Niyonsenga T, Daniel M. Local descriptive body weight and dietary norms, food availability, and 10-year change in glycosylated haemoglobin in an Australian populationbased biomedical cohort. BMC Public Health. 2017;17(1):149.

29. Cruwys T, Bevelander KE, Hermans RCJ. Social modeling of eating: a review of when and why social influence affects food intake and choice. Appetite. 2015;86:3-18.

30. Robinson E, Thomas J, Aveyard P, Higgs S. What everyone else is eating: a systematic review and meta-analysis of the effect of informational eating norms on eating behavior. J Acad Nutr Diet. 2014;114(3):414-29.
31. Vartanian LR, Spanos S, Herman CP, Polivy J. Modeling of food intake: a meta-analytic review. Soc Influence. 2015;10(3):119-36.

32. Pachucki MA, Jacques PF, Christakis NA. Social network concordance in food choice among spouses, friends, and siblings. Am J Public Health. 2011;101(11):2170-7.

33. Tuu HH, Olsen SO, Thao DT, Anh NTK. The role of norms in explaining attitudes, intention and consumption of a common food (fish) in Vietnam. Appetite. 2008;51(3):546-51.

34. Christakis NA, Fowler $\mathrm{JH}$. Social contagion theory: examining dynamic social networks and human behavior. Stat Med. 2013;32(4):556-77.

35. Christakis NA, Fowler $\mathrm{JH}$. The spread of obesity in a large social network over 32 years. New Engl J Med. 2007;357(4):370-9.

36. Christakis NA, Fowler $\mathrm{JH}$. The collective dynamics of smoking in a large social network. New Engl J Med. 2008;358(21):2249-58.

37. Rosenquist JN, Murabito J, Fowler JH, Christakis NA. The spread of alcohol consumption behavior in a large social network. Ann Intern Med. 2010;152(7):426-33.

38. Blok DJ, de Vlas SJ, van Empelen P, van Lenthe FJ. The role of smoking in social networks on smoking cessation and relapse among adults: a longitudinal study. Prev Med. 2017;99:105-10.

39. Blok DJ, de Vlas SJ, van Empelen P, Richardus JH, van Lenthe FJ. Changes in smoking, sports participation and overweight: does neighborhood prevalence matter? Health \& Place. 2013;23:33-8.

40. Hill AB. The environment and disease: association or causation? Proceedings of the Royal Society of Medicine. 1965;58(5):295-300.

41. Daniel M, Moore S, Kestens Y. Framing the biosocial pathways underlying associations between place and cardiometabolic disease. Health \& Place. 2008;14(2):117-32

42. Grant J, Chittleborough C, Taylor A, Dal Grande E, Wilson D, Phillips P, Adams R, Cheek J, Price K, Gill T, Ruffin R. The north West Adelaide health study: detailed methods and baseline segmentation of a cohort for chronic diseases. Epidemiol Perspect Innov. 2006:3:4

43. Taylor AW, Campostrini S, Gill TK, Carter P, Dal Grande E, Herriot M. The use of chronic disease risk factor surveillance systems for evidence-based decision-making: physical activity and nutrition as examples. Int J Public Health. 2010:55(4):243-9.

44. Taylor AW, Dal Grande E, Wu J, Shi Z, Campostrini S. Ten-year trends in major lifestyle risk factors using an ongoing population surveillance system in Australia. Popul Health Metr. 2014;12(1):31.

45. Australian Bureau of Statistics. Statistical Geography Volume 2. Census geographic areas Australia, cat. No. 2905.0. Canberra: Australian Bureau of Statistics; 2001.

46. Australian Bureau of Statistics. Usual Residents Profile 2001, cat. no. 2004.0 [online], cat. No. 10/05/11. Canberra: Australian Bureau of Statistics. p. 2003.

47. Wilcox S, Castro C, King AC, Housemann R, Brownson RC. Determinants of leisure time physical activity in rural compared with urban older and ethnically diverse women in the United States. J Epidemiol Commun H. 2000;54(9):667-72.

48. Australian Bureau of Statistics. Census of Population and Housing. CDATA 2001 Datapack - usual residents profile, 2001, cat. No. 2040.0.30.003. Canberra: Australian Bureau of Statistics; 2001.

49. Grant J, Taylor A, Ruffin R, Wilson D, Phillips P, Adams R, Price K. Cohort profile: the north West Adelaide health study (NWAHS). Int J Epidemiol. 2009;38:1479-86.

50. Bennett CM, Guo M, Dharmage SC. HbA1c as a screening tool for detection of type 2 diabetes: a systematic review. Diabetic Med. 2007;24(4):333-43.

51. Bohannon RW. Comfortable and maximum walking speed of adults aged 20-79 years: reference values and determinants. Age Ageing. 1997;26(1):15-9.

52. Astell-Burt T, Feng X. Geographic inequity in healthy food environment and type 2 diabetes. Med J Australia. 2015;203(6):246-8. e1

53. Jeffery RW, Baxter J, McGuire M, Linde J. Are fast food restaurants an environmental risk factor for obesity? Int J Behav Nutr Phy. 2006;3:2.

54. Reitzel LR, Regan SD, Nguyen N, Cromley EK, Strong LL, Wetter DW, McNeill $\mathrm{LH}$. Density and proximity of fast food restaurants and body mass index among African Americans. Am J Public Health. 2014;104(1):110-6.

55. World Health Organization. Global database on body mass index: an interactive surveillance tool for monitoring nutrition transition. 2014. http:// apps.who.int/bmi/index.jsp. Accessed 11 Sept 2014.

56. National Health and Medical Research Council. Australian dietary guidelines. Canberra: National Health and Medical Research Council; 2013.

57. Australian Bureau of Statistics. National Health Survey: Users' Guide Electronic, cat. no. 4363.0.55.001. Canberra: Australian Bureau of Statistics; 2007. 2008 
58. Murray GD, Findlay JG. Correcting for the bias caused by drop-outs in hypertension trials. Stat Med. 1988;7(9):941-6.

59. Schüle SA, Bolte G. Interactive and independent associations between the socioeconomic and objective built environment on the neighbourhood level and individual health: a systematic review of multilevel studies. PLoS One. 2015;10(4):e0123456.

60. Australian Bureau of Statistics. Basic community profile (BCP) DataPack, cat. No. 20069.0.30.001 (Second Release). Canberra: Australian Bureau of Statistics; 2006.

61. Australian Bureau of Statistics. Australian Standard Geographic Classification Vol. 2: Census geographic areas, Australia 2006. Canberra: Australian Bureau of Statistics; 2006

62. Muthen BO, Muthen LK, Asparouhov T. Regression and mediation analysis using Mplus. Los Angeles, CA: Muthen \& Muthen; 2016.

63. Muthen LK, Muthen BO. Mplus User's Guide. 8th ed. Los Angeles, CA: Muthen \& Muthen; 1998-2017.

64. Arbuckle JL. Full information estimation in the presence of incomplete data. In: Advanced structural equation modeling: issues and techniques. Mahwah, NJ: Lawrence Erlbaum Associates; 1996.

65. Enders CK, Bandalos DL. The relative performance of full information maximum likelihood estimation for missing data in structural equation models. Struct Equ Modeling. 2001;8(3):430-57.

66. Mackinnon DP, Fairchild AJ. Current directions in mediation analysis. Curr Dir Psychol Sci. 2009;18(1):16-20.

67. Gunzler D, Chen T, Wu P, Zhang H. Introduction to mediation analysis with structural equation modeling. Shanghai Archives of Psychiatry. 2013;25(6):390.

68. West BT, Welch KB, Galecki AT. Linear mixed models: a practical guide using statistical software. Boca Raton: Chapman \& Hall/CRC; 2007.

69. Ukoumunne O, Gulliford M, Chinn S, Sterne J, Burney P. Methods for evaluating area-wide and organisation-based interventions in health and health care: a systematic review. Health Technol Asses. 1999;3(5):98.

70. Hruschka DJ, Brewis AA, Wutich A, Morin B. Shared norms and their explanation for the social clustering of obesity. Am J Public Health. 2011;101(S1):S295-300.

71. Ball K, Jeffery RW, Abbott G, McNaughton SA, Crawford D. Is healthy behavior contagious: associations of social norms with physical activity and healthy eating. Int J Behav Nutr Phy. 2010;7(1):86.

72. Marks G, Miller $\mathbf{N}$. Ten years of research on the false-consensus effect: an empirical and theoretical review. Psychol Bull. 1987;102(1):72-90.

73. Mollen S, Rimal RN, Ruiter RAC, Kok G. Healthy and unhealthy social norms and food selection. Findings from a field-experiment. Appetite. 2013;65:83-9.

74. Shu PS, Chan YM, Huang SL. Higher body mass index and lower intake of dairy products predict poor glycaemic control among type 2 diabetes patients in Malaysia. PLoS One. 2017;12(2):e0172231.

75. Baker $\mathrm{AH}$, Wardle J. Sex differences in fruit and vegetable intake in older adults. Appetite. 2003;40(3):269-75.

76. Carroll SJ, Niyonsenga T, Coffee NT, Taylor AW, Daniel M. Does physical activity mediate the associations between local-area descriptive norms, built environment walkability, and glycosylated hemoglobin? Int J Env Res Pub He. 2017;14(9)

77. Daniel M, Lekkas P, Cargo M, Stankov I, Brown A. Environmental risk conditions and pathways to cardiometabolic diseases in indigenous populations. Annu Rev Publ Health. 2011;32:327-47.

78. Robinson E. Perceived social norms and eating behaviour: an evaluation of studies and future directions. Physiol Behav. 2015;152, Part B:397-401.

79. Jacobson RP, Mortensen CR, Cialdini RB. Bodies obliged and unbound differentiated response tendencies for injunctive and descriptive social norms. J Pers Soc Psychol. 2011;100(3):433-48.

80. Lapinski MK, Rimal RN. An explication of social norms. Commun Theor. 2005:15(2):127-47.

81. Schultz PW, Nolan JM, Cialdini RB, Goldstein NJ, Griskevicius V. The constructive, destructive, and reconstructive power of social norms. Psychol Sci. 2007;18(5):429-34.

82. Von Borgstede C, Dahlstrand U, Biel A. From ought to is: moral norms in large-scale social dilemmas. Goteberg. Psychol Rep. 1999;5(29):1-17.

83. Wansink B, Soman D, Herbst KC. Larger partitions lead to larger sales: divided grocery carts alter purchase norms and increase sales. J Bus Res. 2017;75:202-9

84. Versluis I, Papies EK. The role of social norms in the portion size effect: reducing normative relevance reduces the effect of portion size on consumption decisions. Front Psychol. 2016;7:756.
85. Diez Roux AV. Neighborhoods and health: where are we and where do we go from here? Revue d'Epidémiologie et de Santé Publique. 2007;55(1):13-21.

86. Mujahid MS, Diez Roux AV, Morenoff JD, Raghunathan T. Assessing the measurement properties of neighborhood scales: from psychometrics to ecometrics. Am J Epidemiol. 2007;165(8):858-67.

87. Auchincloss AH, Mujahid MS, Shen M, Michos ED, Whitt-Glover MC, Diez Roux AV. Neighborhood health-promoting resources and obesity risk (the multi-ethnic study of atherosclerosis). Obesity. 2013;21(3):621-8.

88. Christine PJ, Auchincloss AH, Bertoni AG, et al. Longitudinal associations between neighborhood physical and social environments and incident type 2 diabetes mellitus: the multi-ethnic study of atherosclerosis (MESA). JAMA Intern Med. 2015;175(8):1311-20.

89. Ragland DR. Dichotomizing continuous outcome variables: dependence of the magnitude of association and statistical power on the cutpoint. Epidemiology. 1992;3(5):434-40.

90. Gorber SC, Tremblay M, Moher D, Gorber B. A comparison of direct vs. selfreport measures for assessing height, weight and body mass index: a systematic review. Obes Rev. 2007;8(4):307-26.

91. Miller TM, Abdel-Maksoud MF, Crane LA, Marcus AC, Byers TE. Effects of social approval bias on self-reported fruit and vegetable consumption: a randomized controlled trial. Nutri J. 2008;7(1):18.

92. Marshall BDL, Galea S. Formalizing the role of agent-based modeling in causal inference and epidemiology. Am J Epidemiol. 2015;181(2):92-9.

93. Auchincloss AH, Diez Roux AV. A new tool for epidemiology: the usefulness of dynamic-agent models in understanding place effects on health. Am J Epidemiol. 2008;168(1):1-8.

94. Hammond RA. Complex systems modeling for obesity research. In: Preventing chronic disease; 2009. http://www.cdc.gov/pcd/issues/2009/jul/ 09_0017.htm. Accessed 1 Mar 2017.

95. El-Sayed AM, Scarborough P, Seemann L, Galea S. Social network analysis and agent-based modeling in social epidemiology. Epidemiologic Perspectives and Innovations. 2012;9(1):1.

\section{Ready to submit your research? Choose BMC and benefit from:}

- fast, convenient online submission

- thorough peer review by experienced researchers in your field

- rapid publication on acceptance

- support for research data, including large and complex data types

- gold Open Access which fosters wider collaboration and increased citations

- maximum visibility for your research: over $100 \mathrm{M}$ website views per year

At BMC, research is always in progress.

Learn more biomedcentral.com/submissions 